\title{
The Important function and Application of Business Etiquette in Business contacts
}

\author{
Chen Min
}

College of science and technology, Jiangxi University of Traditional Chinese Medicine, Nanchang Jiangxi 330004, China

Key words: Business etiquette; Business contacts; Function and application

\begin{abstract}
As a state of ceremonies, China has a long history and profound in the etiquette culture. Business etiquette is an art form in business contacts, which is used in clothing, meeting and conversation during business contacts to maintain the image of the enterprise or individual. It is an important way to show friendliness and respect to the communication objects. This article made a discussion on the important function and application of business etiquette in business contacts.
\end{abstract}

\section{Introduction}

No matter for individuals or enterprises, etiquette plays a very important role. It is not only the reflection of a personal cultivation but also the reflection of corporate culture literacy. Confucius, our great educator once said "To cultivate one's morality, to hold a family business and to govern the country". ${ }^{1}$ Especially in today's society in which the competition pressure is great and the information flow is fast, only to maintain a good corporate image can the enterprise keep advantage in social competition. Etiquette is a behavioral science which originated from people's lives, and the emergence of business etiquette is the specific form of etiquette in the social science. Business etiquette, which is focused on the expression of respect, is a kind of behavioral norms for people to show respect. It is extensive and detailed, with particular attention to some contact details, including a lot of communication skills.

\section{The important function of business etiquette in business contacts}

\subsection{To improve personal qualities}

Personal qualities are the basic qualities one should have in the business contacts, as well as the ultimate element of competition in the market. Communication details can show one's cultivation and quality. For example, a cultivated person will neither smoke in front of strangers nor speak loudly in public. A cultivated person will be particular about the dressing and adornment. It is best to wear not more than three sorts of simple and graceful adornments which are suit for the identity, and not more than two for each sort of adornment, being coordinated with clothes with soft color and without too big contrast. ${ }^{2}$

\subsection{To establish a good interpersonal relationship}

Business contact is to cooperate, influence and have function mutually. Only when we make a certain code of conduct can we maintain the cooperation harmoniously and friendly. The existence of etiquette is to tell people what should do in the business contacts, what should not do and how to do it to help people establish a good relationship with others and keep good friendship.

\subsection{To maintain personal and corporate image}

The image of an enterprise requires the participation of every employee, and a good corporate image can help enterprises to gain competitive advantage. An enterprise with negative image will eventually fall if it can't change its image in the public. Enterprise's business and negotiation is mainly done by the staff. If the staff personal temperament and quality is good and he understands business etiquette, it will help the success of negotiation. In two companies negotiate business we should not only pay attention to the ability of the enterprise, but also the personnel quality and cultivation of the enterprise, because high quality and self-cultivation can give each other a good impression and promote the success of the cooperation. And the direct method to shape the image is 
the business etiquette. In business contacts it will bring people civilization when complying with the mannerisms etiquette and it will make people feel confident when complying with the dressing and adornment etiquette ${ }^{3}$. Therefore, the use of business etiquette in business contacts can establish a good personal and corporate image, and help the enterprise keep advantage in the market competition, so as to improve the economic and social benefits.

\subsection{To promote the relationship between business people}

With the deepening of association, the two sides will produce emotional experience which maybe a kind of emotional resonance or a kind of emotional rejection. Good business etiquette can enhance the emotional resonance between each other and promote the construction and maintaining of a good relationship. Likewise, if one doesn't pay attention to business etiquette, it will make him appear vulgar and it is easy to produce emotional repellent so the relationship will develop to the bad direction.

\subsection{To improve the benefits of the business activities}

Business etiquette can bring huge hidden benefits to business activities. Here is a story about business etiquette, a department manager showed the partners around the factory, the partners are very satisfied with the whole process and are ready to sign a contract, but just at that time, the department manager made an amazing behavior, he spitted on the ground. When the partners saw this they gave up the signing of the contact ${ }^{4}$. From this story we can see that individual business etiquette is directly related to the benefit of the enterprise business activity.

\section{The Application of Business Etiquette in Business Contacts}

\subsection{Meeting etiquette}

Meeting etiquette is very important in business contacts, because whether the first impression is good or bad will produce great influence for subsequent exchanges and cooperation. When people don't know each other, it is the first impression that helps them to make judgments. And emotional experience has already occurred at that time, whether it is emotional resonance or rejection comes from the first impression. One of the most important meeting etiquette in business contacts is handshaking which has great wisdom. First of all, the principle of handshake sequence is "seniors first" which means seniors will reach out hand first. When meeting guests, masters hand first and then guests. On the contrary, when leaving guests hand first and then masters. Left hand should not be used when shaking hands, even sunglasses, hats and gloves are not allowed to wear, and when shaking with the opposite sex, it is not allowed to use both hands ${ }^{5}$.

Apart from handshake etiquette, meeting etiquette also includes bow and greeting etiquette. The main forms of greeting etiquette are taking off hat, nodding, bowing, Namaste and so on, which are used to express respect to each other. The order of the greeting etiquette is subordinate to the superior, the younger generation to elders, men to women and low status to high status.

Greetings are also needed in addition to meeting etiquette. It also has a certain order. Master first greets guest, subordinate first greets superior, man first greets woman, which is regarded as social morality. The address is also very important when greeting to each other. It is general to address woman as Miss or madam, and to address man as Mr. Madam and sir are often used in foreign enterprises.

\subsection{The Mannerism Etiquette}

There is such a story, a student was always late and absent from class. Once a professor asked his name during the roll call, and the student said that his name was not important, so the professor did not say anything and continued to call the roll, however, there were few students coming to listen to his class. There was also a scholar with high achievement and good reputation in academia. Once he held open lectures at the university and all seats were occupied. During the interaction with students he asked a student's name who said his name was not important. While the scholar said, "No, it is very important for me." The student was moved because he won respect. This is the why the professor can only be professor and scholar can be scholar.

This example tells us that respect is regardless of age, occupation and seniority. If one wants to receive the respect of others, he should set up a good communication image and start from the 
respect for others. Mannerism etiquette is a person's internal concrete performance from which we can see his quality level. During business contacts one needs to be polite and self-controlled, and avoid various uncivilized behavior and habits. When you need to enter someone's office or room for issues to discuss, you need to knock on the door or ring the bell first, but should grasp the time length, neither too short nor too long. Only when the owner agreed can you come in. Otherwise you should not enter into the room ${ }^{6}$. Develop good habits consciously in our daily life and avoid all kinds of uncivilized behaviors. During business contacts, be sure not to make the following behaviors in front of the customers, friends or colleagues, such as ear cleaning, blowing your nose, yawning, sneezing, coughing or teeth picking. If you can't help doing this, you should turn aside and use tissue to cover your face, avoid loud noise and throw the rubbish into rubbish bin. Details can highlight a person's cultivation. During business contacts it is detail that we should pay more attention to because the impression to a person is also from details.

In the business contacts, to be courteous, natural and graceful, self-controlled, manners etiquette is very important. A person's manner can be presented from many ways, which is the embodiment of the external behavior, such as sit, stand, walk, hand gestures, etc., and it is a kind of silent language, but most of time it is more powerful and influential than words. What it presents is one's etiquette education and the mental state.

\subsection{Appearance Etiquette}

Appearance is also very important communication etiquette in business contacts. It plays an important role in business negotiation and job application. Women in the workplace need to pay attention to the etiquette rules of dressing: first, black leather skirt is forbidden in formal occasion, it is an international rule because leather skirt makes people feel not so serious. Second, legs are not allowed to be bare in advanced and formal places. Third, the dress can't appear broken and need to maintain clean and tidy. Fourth, choose shoes and socks to match dress. Slippers are forbidden and socks should not be worn with sandals. When wearing formal suit sandals you wear can not reveal the heel and toe.

Men tend to wear a suit in the business contacts, a suit is the symbol of identity, and wearing suit takes a lot of learning. The wearing of suit is professional. There are three main points and principles, specifically speaking, the number of colors of whole body can not be more than three, and three colors here refer to three color systems. Shoes, belts and briefcase reflects the principle that is the color of the above three items should be the same, mainly black. There are three taboos, first tear down the trademark and tags of the suit ${ }^{7}$. Second strictly choose the color and material of socks, formal occasions can't wear white socks, mainly black and dark, and socks color should be coordinated with the shoes. The third is the tie of the method. Tie adjustment mainly based on color and fabric, for example, cross knot is suit for elegant and thin tie. Ties are not needed when wearing short-sleeved shirts, jackets, and non business attire, Tie method mainly has three requirements: one is man's dimples. Second is not to use stickpin, the use of the tie clip has specific provisions. It is used in the VIP status or dress professionally. The best position of tie clip is between the third and the fourth button of the shirt. On the tie clip with clear career identity, their identity and occupation have obvious effect. Third is the length of the tie, tie best position of the arrow side is above the belt buckle, too long and too short will reduce the aesthetic effect.

\section{Summary}

Business etiquette in business contacts is of great practical significance. It is the best presence for the cultivation of a person. Learning business etiquette can improve a person's accomplishment and quality. About business etiquette, Bill. Gates once said "enterprise competition is the competition of staff quality". Though employees are a small part of enterprise, their functions in the representative and propaganda enterprise image are very large, and the competition of the quality among employees is the competition between enterprises and also important way for the enterprises to keep advantages. No matter in business contacts or ordinary contacts one's cultivation is presented in details and the detail is the embodiment of the quality of a person. The reason that our country attaches great importance to the role of manners most depends on its coagulating power 
effect, that is also the reason why Confucius maintain Zhou etiquette during Spring and Autumn Period and our country attaches great importance to the development of etiquette.

Etiquette can adjust the relationship of people, improve the affection between each other and maintain friendly contacts. If it can be carried out in accordance with the standard etiquette in communication and discipline yourself, it can help establish a good relationship between people, build a good emotional bridge, form mutual trust, mutual respect, friendly and mutually beneficial relations, so as to promote the friendly cooperation and mutual benefit, obtain better social and economic benefits. In conclusion etiquette is the important basis for the development of a person or enterprise. Especially in today's competitive society, more attention should be paid to image, and realize the synchronous development of etiquette, knowledge and wisdom.

\section{References}

[1] Wang Miao miao, Zhang Zhi. On the Application of Business Etiquette in Business Contacts [J]. Pioneering with Science \& Technology Monthly, 2010, 23 (12): 253-254.

[2] Guo Hua. On the Role of Business Etiquette in Business Activities [J]. Heilongjiang Science and Technology Information, 2009 (26): 213-213.

[3] Wang Wenli. Analysis to the Application of Business Etiquette in Business Negotiation [J]. China Business \& Trade, 2011 (29): 53-54.

[4] Zhang Jinqiao. On the Rational Use of Commercial Etiquette in Business Negotiation [J]. Youth Literator, 2013 (23): 214-214.

[5] Gao Lijuan. Analysis on the Application of Business Etiquette in International Business Activities [J]. Journal of Mu Danjiang Normal University (philosophy and social science edition), 2015 (2): 53-54.

[6] Du Juan. Study on the Application of Business Etiquette in Business Communication, the application of research [J], 2015 (32): 107-107.

[7] Li Qian, Wang Jian, Li Peng. On the Importance of Business Etiquette in Business Negotiation [J]. The Guide of Science \& Education: electronic Edition, 2013 (9): 124-124. 